\title{
Defining normal vertebral end plates Cobb angle from T12 to L4 using computerized tomography in Sudanese populations
}

\author{
Caroline Edward Ayad", Elsafi Ahmed Abdalla, Amel Mohamed Osman, \\ Mohamed Elfadil Mohammed
}

Radiology Department, College of Medical Radiological Science, Sudan University Of Science and Technology, Khartoum, Sudan

\section{Email address:}

carolineayad@yahoo.com, carolineayad@sustech.com(C. E. Ayad),dr.Elsafi@gmail.com,dr.Elsafi@sustech.com (E. A. Abdalla), amelOsman@yahoo.com(A. M. Osman), mohamedeelfadil@yahoo.com(M. E. Mohammed)

\section{To cite this article:}

Caroline Edward Ayad, Elsafi Ahmed Abdalla, Amel Mohamed Osman, Mohammed Elfadil Mohammed. Defining Normal Vertebral End Plates Cobb Angle from T12 to L4 Using Computerized Tomography in Sudanese Populations. International Journal of Medical Imaging. Vol. 1, No. 3, 2013, pp. 66-70. doi: 10.11648/j.ijmi.20130103.15

\begin{abstract}
The aim of this study is to establish normal values as reference for vertebral end plate from T12 to L4 in normal Sudanese subjects using computerized tomography (CT).130 lateral scout CT scans done using GE Healthcare machine with KV120, MA10-50 for lumber vertebra were obtained from subjects (65 males and 65 females) their ages ranged from (15-74) years old .Endplates angle from T12 to L4 were measured using Cobb Method for both genders and the data were correlated to their ages. For males the endplates mean angles were found to be $7.4 \pm 3.5,6.6 \pm 3.3,4.7 \pm 2.9,5.3 \pm 3.8,18.8 \pm 7.6$ and for females $9.2 \pm 4.5,9.9 \pm 4.5,9.7 \pm 4.2,6.8 \pm 4.3,5.9,4.6$ for T12,L1,L2,L3and L4 respectively. The research also studied the difference according to gender; it showed significant difference at $p$ value 0.05 , the end plates angles were affected as the subjects ages increase. The study concluded that the mean Cobb angle end plate differs significantly from males and females Sudanese subjects and it has relation with age and the values differs from what was mentioned in the previous studies, the knowledge of the normal end plates angle allows better characterization and diagnosis for vertebra from T12 to L4.
\end{abstract}

Keywords: End Plates, Cobb Angle, Lumber, CT

\section{Introduction}

The spine is an anatomical structure of repetitive motion and large compressive forces and therefore will be of high risk of degenerative changes. [1].

Knowledge of the bony anatomy of the spine, especially of the vertebral endplate, is necessary for evaluation of the normal vertebra or cases that needs surgery. Numerous investigators have conducted studies offered specific information on the vertebral morphology in the sagittal and coronal planes [2-6] but still there is a lack of studies concerning the geometry of vertebral endplates.

The vertebral endplate is a thin layer of dense, subchondral bone adjacent to the intervertebral disc, which tends to be thinnest in the central region and thickest towards the periphery [7].

Wedging of the vertebral bodies is a recognized normal anatomic feature [8]. The thoraco lumbar junction is the

most common location for diseases [9,10]. Traumatic fractures commonly occur between T12andL2 $[8,11]$,therefore, it can sometimes be difficult to differentiate between fractures and normal anatomic wedging [12].

Evaluation of bone morphology is important; the shape changes associated with normal aging are still under debate. There is no consensus on whether a mild wedging of the vertebral body is the result of a continuous remodeling with the advancing age or due to fractures. To be able to diagnose morphological changes, the normal should be well known [1].

Several techniques have been described to quantify vertebral deformity. [8, 13-15],Cobb [16] and Ferguson [17] have described methods for measuring curvature of the spine .Cobb angle measurements give orthopedic surgeons 
information about spinal deformities and help in treatment decision. Generally, the patient needs surgery when the cob angle is higher than 40degrees. The Cobb angle is the strongest factor in the determination of the severity of scoliosis [18].Therefore, the Cobb angle for normal subjects needs to be known in order to exclude the diseased or any abnormality.

\section{Objectives}

The purpose of this study is to find out the normal cobb angle for vertebral end plates from Twelve's Thoracic Vertebra (T12) to Fourth Lumber Vertebra (L4) in order to help the surgeon in the surgery decision and to establish standard values for Sudanese population and to correlate the findings with the age and gender .To our knowledge, no study was done for Sudanese in the open literature related to the normal vertebral end plates Cobb angles.

\section{Materials and Methods}

The study was done at Soba Hospital, Yastabshiroon Medical Centers, Bugaa Specialized Hospital, and Imperial Hospital during the period from 2010 November to 2011 July.

130 Sudanese patients in both genders ( 65 males and 65 females) with different ages were included; all had CT examination for spine. All lateral scouts for spine were taken, all were diagnosed as normal. Traumatic cases, any disease of the vertebral column, spinal canal, Para vertebral muscles diseases cases were excluded.

GE Healthcare CT scanner was used. The exposure factors were KVp120, MA10-50. Patients lied on the examination table in supine position with feet first and hands behind the head and there are bands under his feet and another one under his head and the isocenter is in xphisternal process then scout views were obtained.

Measurements were taken by drawing a perpendicular to a line drawn across the superior endplate of the upper-end of T12,L1,L2,L3,L4 vertebra and the inferior endplate of the lower-end of the same vertebra; the angle formed by the intersection of the two perpendicular lines is the Cobb angle.

The data were analyzed using SPSS program version16.Independent T-test, simple tables including frequency and percentages, and p-value for testing the results significances of the variables were used; $\mathrm{P}$ value is significant when $<0.05$.

\section{Results}

The following tables and figures presented the results.
Table 1. shows males results including age classes, mean and standard deviation of Cobb angle from T12 to L4.

\begin{tabular}{cccccc}
\hline & \multicolumn{5}{c}{ Variation } \\
Age & T12 & L1 & L2 & L3 & L4 \\
Classes & $\begin{array}{c}\text { Mean } \pm \\
\text { SD }\end{array}$ & $\begin{array}{c}\text { Mean } \pm \\
\text { SD }\end{array}$ & $\begin{array}{c}\text { Mean } \pm \\
\text { SD }\end{array}$ & $\begin{array}{c}\text { Mean } \pm \\
\text { SD }\end{array}$ & Mean \pm SD \\
\hline $15-24$ & $4.4 \pm 3.3$ & $3.6 \pm 2.9$ & $2.9 \pm 1.8$ & $5.0 \pm 2.5$ & $15.4 \pm 6.0$ \\
$25-34$ & $8.4 \pm 4.7$ & $7.3 \pm 4.5$ & $6.7 \pm 3.2$ & $6.0 \pm 6.0$ & $20.3 \pm 8.1$ \\
$35-44$ & $6.6 \pm 4.8$ & $7.1 \pm 2.3$ & $3.5 \pm 1.3$ & $3.8 \pm 3.2$ & $20.0 \pm 7.1$ \\
$45-54$ & $7.8 \pm 2.9$ & $6.9 \pm 2.7$ & $4.8 \pm 3.6$ & $6.2 \pm 4.3$ & $19.8 \pm 10.4$ \\
$55-64$ & $6.9 \pm 2.8$ & $6.9 \pm 2.4$ & $3.8 \pm 2.0$ & $3.4 \pm 1.8$ & $16.2 \pm 4.6$ \\
$65-74$ & $7.8 \pm 3.6$ & $6.7 \pm 3.6$ & $4.6 \pm 2.4$ & $5.8 \pm 2.5$ & $19.7 \pm 6.7$ \\
\hline
\end{tabular}

Table 2. shows females results including age classes, mean and standard deviation of cobb angle from T12 toL4.

\begin{tabular}{|c|c|c|c|c|c|}
\hline \multirow{3}{*}{$\begin{array}{c}\text { Age } \\
\text { Classes }\end{array}$} & \multicolumn{5}{|c|}{ Variation } \\
\hline & T12 & L1 & L2 & L3 & L4 \\
\hline & $\begin{array}{c}\text { Mean } \pm \\
\text { SD }\end{array}$ & $\begin{array}{c}\text { Mean } \pm \\
\text { SD }\end{array}$ & $\begin{array}{c}\text { Mean } \pm \\
\text { SD }\end{array}$ & $\begin{array}{c}\text { Mean } \pm \\
\text { SD }\end{array}$ & $\begin{array}{c}\text { Mean } \pm \\
\text { SD }\end{array}$ \\
\hline $15-24$ & $10.0 \pm 5.0$ & $9.8 \pm 4.7$ & $9.0 \pm 3.5$ & $7.8 \pm 5.3$ & $5.2 \pm 3.4$ \\
\hline $25-34$ & $8.5 \pm 3.8$ & $9.5 \pm 3.7$ & $10.0 \pm 3.2$ & $5.7 \pm 3.2$ & $5.4 \pm 3.2$ \\
\hline $35-44$ & $8.4 \pm 4.3$ & $9.5 \pm 3.6$ & $9.4 \pm 3.5$ & $5.9 \pm 2.3$ & $4.8 \pm 3.6$ \\
\hline $45-54$ & $9.9 \pm 4.5$ & $11.1 \pm 4.4$ & $10.5 \pm 3.8$ & $7.0 \pm 3.1$ & $6.5 \pm 4.5$ \\
\hline $55-64$ & $10.2 \pm 6.7$ & $9.3 \pm 7.5$ & $9.7 \pm 8.0$ & $7.4 \pm 8.2$ & $9.0 \pm 8.5$ \\
\hline $65-74$ & $7.4 \pm .7$ & $9.5 \pm 1.1$ & $10.0 \pm 3.7$ & $8.2 \pm 1.8$ & $4.3 \pm 1.1$ \\
\hline
\end{tabular}

Table 3. shows Total sample results including age classes, mean and standard deviation, P-Value of Cobb angle from T12 to L4.

\begin{tabular}{cccccc}
\hline $\begin{array}{c}\text { Vertebra } \\
\text { Level }\end{array}$ & Gender & $\mathrm{N}$ & Mean & \pm STDV & $\begin{array}{c}\text { Sig } \\
(2 \text { tail })\end{array}$ \\
\hline T12 & Male & 65 & 7.4 & 3.5 & $0.012^{*}$ \\
& Female & 65 & 9.2 & 4.5 & \\
L1 & Male & 65 & 6.6 & 3.3 & $0.000^{*}$ \\
& Female & 65 & 9.9 & 4.5 & \\
L2 & Male & 65 & 4.7 & 2.9 & $0.000^{*}$ \\
& Female & 65 & 9.7 & 4.2 & \\
L3 & Male & 65 & 5.3 & 3.8 & $0.042^{*}$ \\
& Female & 65 & 6.8 & 4.3 & \\
\hline L4 & Male & 65 & 18.8 & 7.6 & $0.000^{*}$ \\
\hline
\end{tabular}

*P-value is significant at 0.05 . 


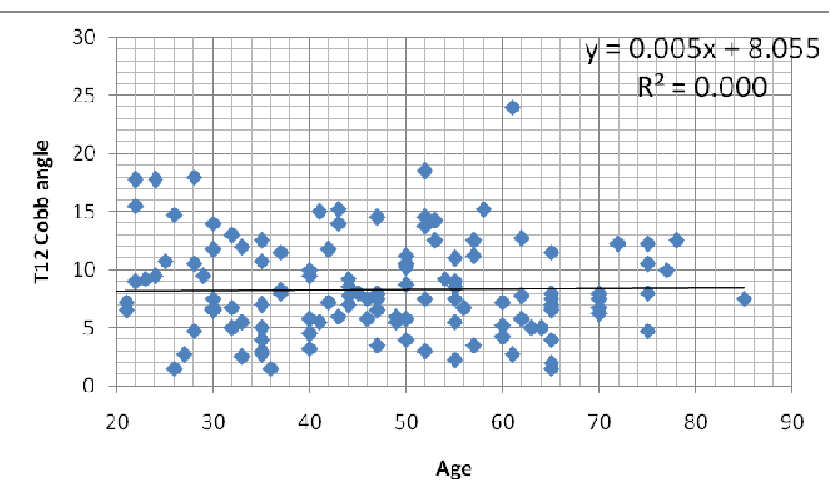

Figure 1. Scatter plot diagramme shows the linear relationship between the subject's age and T12Cobb angle.

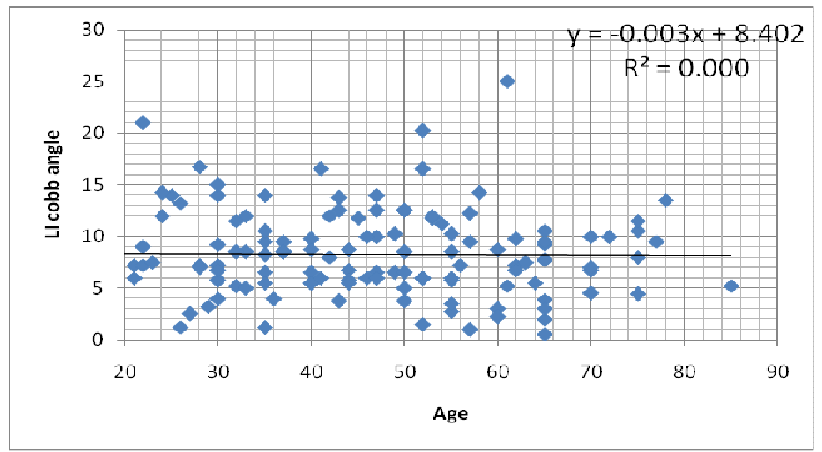

Figure 2. Scatter plot diagramme shows the linear relationship between the subject's age and L1Cobb angle.

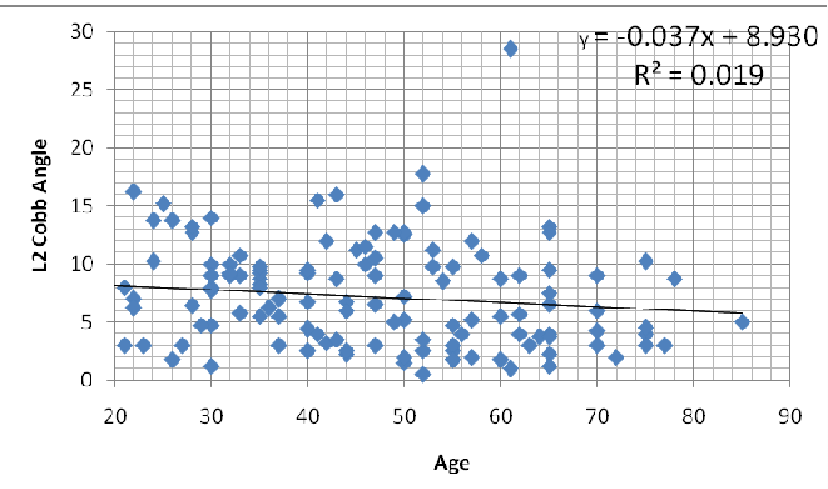

Figure 3. Scatter plot diagramme shows the linear relationship between the subject's age and L2Cobb angle.

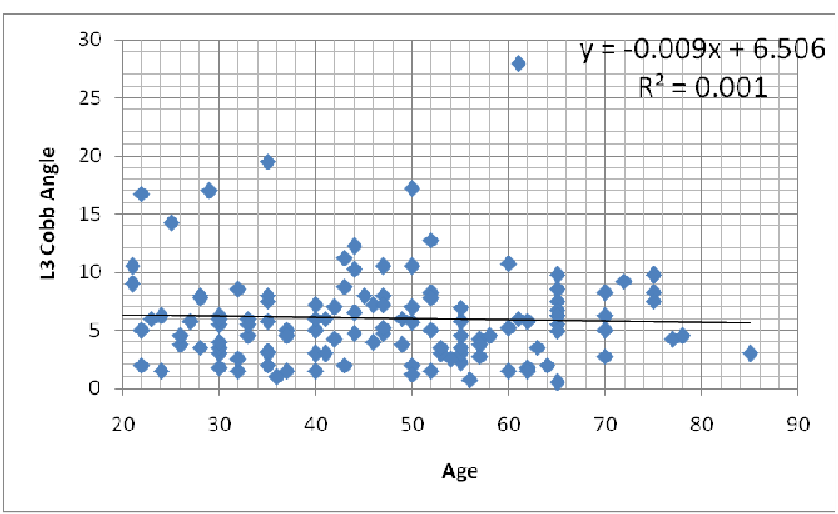

Figure 4. Scatter plot diagramme shows the linear relationship between the subject's age and L3Cobb angle.

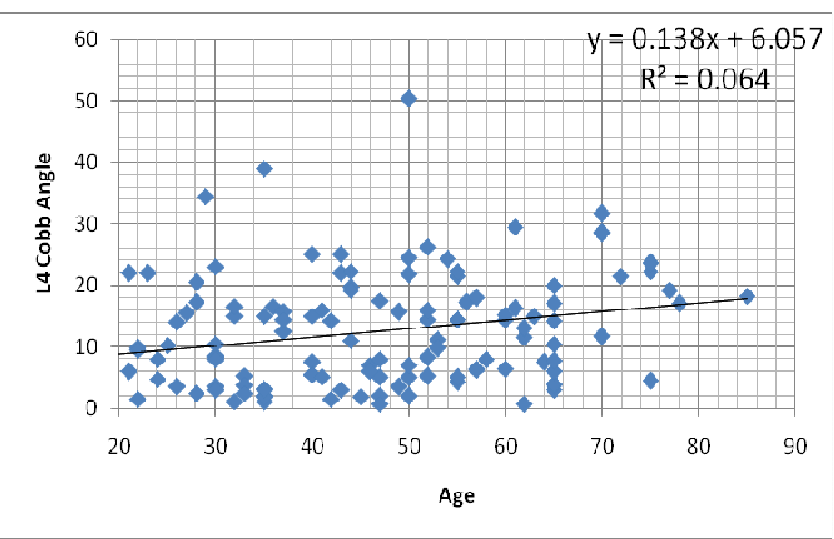

Figure 5. Scatter plot diagramme shows the linear relationship between the subject's age and L4Cobb angle.

\section{Discussion}

The aim of this study is to establish normal values as reference for vertebral endplate from T12 to L4 in normal Sudanese subjects using computerized tomography (CT) as well as to correlate the findings with gender and age.

130 lateral scout CT scans for spine were obtained from subjects (65 males and 65 females ), their ages ranged from(15-74)years old and were done using GE Healthcare machine with KV120, MA10-50 .Endplates angle from T12 to L4 were measured using Cobb method for both genders and the data were correlated to their ages.

The ages for males were classified to different groups ; the measurements were presented in (table 1)as mean values for $\mathrm{T} 12 \mathrm{Cobb}$ angle endplate as well as L1,L2,L3and L4 for each group of ages, also for females all the measurements were done for to each group of age .(table 2)

The Cobb method [19] was one of the first methods for the evaluation of sagittal spinal curvature. The use of vertebral endplate lines to construct angles on sagittal radiographs is often termed the modified Cobb method [20], and was used to evaluate cervical lordosis [21], thoracic kyphosis and lumbar lordosis [22], and to perform segmental angulations analysis [23].

As the Cobb method is influenced by the orientation of vertebral end plate tilt [24]; the mean Cobb angle is smaller for male as it is found to be for T12 is $\left(7.4^{0}\right),\left(6.6^{0}\right)$ for L1, $\left(4.7^{0}\right)$ forL2, $\left(5.3^{0}\right)$ forL3, but when measuring the angle for L4 it is found to be greater than females.

The measurements were done for both males and females, there were significant differences between males and females Cobb angle for T12,L1,L2,L3 and L4 at $p$-value 0.05 . The difference between the T12 between males and females as $p$-value is found to be $0.012, \mathrm{~L} 1$ is $0.000, \mathrm{~L} 2$ is $0.000, \mathrm{~L} 3$ is 0.042 , and L 4 is 0.000

Another reverse study [12] had measured the mean angle for T12, L1; they found that the angle was slightly greater in men than women at $\mathrm{T} 12$ and the converse was true at L1. They had mentioned that neither of these was statistically significant. They also had mentioned that the normal ranges 
for both levels and sexes are therefore very similar; their findings differ from previously published data in which men appear to consistently have a greater degree of vertebral wedging than women [25] however our study is consistent with the study done by [25]

The presented figures correlate between the age and the Cobb angle from T12 to L4. There were linear relationships, as the age increased the angle was decreased except for L4 it increases.By applying the following equation the L4 Cobb angle can be estimated:

$$
\text { L4 Cobb angle }=0.14 \text { Xage }+6.1 \quad \mathrm{Eq}: 1
$$

This relationship is for the whole sample including both genders .Although wedging in the women is constant before menopause; postmenopausal women have an increased incidence relative to men of a similar age. The difference in the measurements of vertebral wedging in different age group reflects that the vertebral morphology changed due to age [1]

The increase in endplate size can also be explained by the growth of bone spurs at the vertebral rim, known as osteophytes [26]. The vertebral body endplates have shown to become more concave with age [27] which is believed to be the result of a decreased structural integrity of the mid vertebral body.

The study done by [12] mentioned that the end plate angle for T12,L1was found to be (0-9 degrees) and readings more than 10 was considered to be out of the normal values; but our study showed that the male Sudanese subjects may have 18.8 degrees and they were diagnosed as normal subjects vertebra.

The study concluded that the mean Cobb angle end plate differs significantly from males and females Sudanese subjects and it has relation with age and the values differ from what was mentioned previously.

\section{References}

[1] W. Tristan, M.Luis. B,Del, D. Silvana Gregorio,M. Jorge Sierra,H.Ludovic,and F.Alejandro Frangi Age-Related Changes in Vertebral Morphometry by Statistical Shape Analysis MeshMed, LNCS 7599, .(2012). pp. 30-39

[2] JL Berry, JM Moran, WS Berg et al A morphometric study of human lumbar and selected thoracic vertebrae. Spine (1987) $12: 362-367$

[3] MM. Panjabi, V .Goel, T. Oxland et al Human lumbar vertebrae. Quantitative three-dimensional anatomy. Spine (1992) 17:299-306

[4] I,.Gilad ,M. Nissan A study of vertebra and disc geometric relations of the human cervical and lumbar spine. Spine(1986) 11:154-157

[5] LT Hall, SI Esses, PC Noble et al Morphology of the lumbar vertebral endplates. Spine (1998) 23:1517-1522

[6] SH Zhou, ID McCarthy, AH McGregor et al Geometrical dimensions of the lower lumbar vertebrae - analysis of data from digitized CT images. Eur Spine J (2000) 9:242-248

[7] WT Edwards, Y Zheng, LA Ferrara et al Structural features and thickness of the vertebral cortex in the thoracolumbar spine. Spine (2001) 26:218-225

[8] JC. Gallagher, LR. Hedlund, S .Stoner, C .Meeger,Vertebral morphometry: normative data. Bone Miner; .( 1988)4:189 $-196$

[9] RM. Ali, DW. Green, TC .Patel. Scheuermann's kyphosis. Curr Opin Pediatr; (1999)11:70 -75

[10] CB .Tribus. Scheuermann's kyphosis in adolescents and adults: diagnosis and management. J Am Acad Orthop Surg; 19986:36 -43

[11] EV.McCloskey , TD. Spector, KS .Eyres, et al. The assessment of vertebral deformity: a method for use in population studies and clinical trials. Osteoporos Int; (1993)3 : 138-147

[12] B .Michael. Crawford, P .Andoni. Toms and Lee Shepstone Defining Normal Vertebral Angulation at the Thoracolumbar JunctionAJR; ( 2009)193:W33-W37.

[13] KK. Jensen, L .Tougaard. A simple x-ray method for monitoring progress of osteoporosis. Lancet; (1981)2 : 19-20

[14] DM .Black, SR .Cummings, K. Stone, E. Hudes, L .Palermo, $\mathrm{P}$.SteigerA new approach to defining normal vertebral dimensions. J Bone Miner Res; .( 1991)6:883-892

[15] G. Leidig, HW .Minne, P .Sauer, et al. A study of complaints and their relation to vertebral destruction in patients with osteoporosis. Bone Miner; (1990)8 : 217-229

[16] JR Cobb:OutLine for the study of scoliosis Am Acad Orthop Sur Instruct Lect 19485:261-275.

[17] AB Ferguson : The study and treatment of scoliosis . South Med J(1930)23:116-120

[18] K. A. Greiner Adolescent idiopathic scoliosis: Radiologic decision-making. American Family Physician, (2002 ). 65(9), 1817-1823.

[19] J. Cobb Outline for the study of scoliosis. Am Acad Orthop Surg Instr Course Lect.; (1948)5:261-275

[20] DE Harrison, R Cailliet, DD Harrison, T.Janik B Holland. Reliability of centroid, Cobb, and Harrison posterior tangent methods: which to choose for analysis of thoracic kyphosis. Spine.2001;26:E227-E234.doi:10.1097/00007632-2001060 10-00002

[21] P .Côté, J. Cassidy, K. Yong-Hing, J .Sibley, J. Loewy. Apophysial joint degeneration, disc degeneration, and sagittal curve of the cervical spine: can they be measured reliably on radiographs? Spine. (1997) 22:859-864.

[22] S .Voutsinas, G .MacEwen. Sagittal profiles of the spine. Clin Orthop Relat Res. (1986);210:235-242.

[23] M .Bernhardt, K .Bridwell. Segmental analysis of the sagittal plane alignment of the normal thoracic and lumbar spines and thoracolumbar junction. Spine. 1989;14:717-721

[24] KP.Singer, TJ. Jones,Breidahl, A comparison of radiographic and computer assited measurements of the thoracic and thoracolumber sagittal curvature .Skeletal Radiol; (1990)19:21-6 
[25] KN .Lauridsen, A .De Carvalho, AH. Andersen. Degree of vertebral wedging of the dorso-lumbar spine. Acta Radiol Diagn (Stockh); (1984)25:29 -32

[26] Z.Klaassen, , R.Tubbs, N.Apaydin, R.Hage, , R.Jordan, M.Loukas,: vertebral spinal osteophytes. Anatomical Science International (2011) 86, 1-9
[27] Z.Shao, G..Rompe, M.Schiltenwolf,: Radiographic Changes in the Lumbar Intervertebral Discs and Lumbar Vertebrae with Age. Spine (2002)27(3), 263-268 